\title{
Transfer of terpenes from essential oils into cow milk
}

\author{
J. Lejonklev, ${ }^{\star 1}$ M. M. Løkke, ${ }^{\star} †$ M. K. Larsen, ${ }^{\star}$ G. Mortensen, ${ }^{\star}$ M. A. Petersen, $\ddagger$ and M. R. Weisbjerg§ \\ ${ }^{*}$ Department of Food Science, and \\ †Department of Engineering, Aarhus University, Tjele, DK-8830, Denmark \\ ‡Department of Food Science, University of Copenhagen, Copenhagen, DK-1958, Denmark \\ $\S$ Department of Animal Science, Aarhus University, Tjele, DK-8830, Denmark
}

\section{ABSTRACT}

The objective of this study was to investigate the transfer of volatile terpenes from caraway seed and oregano plant essential oils into cow's milk through respiratory and gastrointestinal exposure. Essential oils have potential applications as feed additives because of their antimicrobial properties, but very little work exists on the transfer of their volatile compounds into milk. Lactating Danish Holstein cows with duodenum cannula were used. Gastrointestinal exposure was facilitated by infusing the essential oils, mixed with deodorized sesame oil, into the duodenum cannula. Two levels were tested for each essential oil. Respiratory exposure was facilitated by placing the animal in a chamber together with a sponge soaked in the essential oils. All exposures were spread over $9 \mathrm{~h}$. Milk samples were collected immediately before and after exposure, as well as the next morning. Twelve monoterpenes and 2 sesquiterpenes were analyzed in essential oils and in milk samples using dynamic headspace sampling and gas chromatography-mass spectrometry. In the essential oils, almost all of the terpenes were detected in both essential oils at various levels. For caraway, the monoterpenes limonene, carvone, and carvacrol were most abundant; in oregano, the monoterpenes carvacrol and $\rho$-cymene were most abundant. For almost all treatments, an immediate effect was detected in milk, whereas little or no effect was detected in milk the following day. This suggests that the transfer into milk of these volatile terpenes is fast, and that the milk will not be influenced when treatment is discontinued. Principal component analysis was used to elucidate the effect of the treatments on the terpene profile of the milk. Terpene content for treatment milk samples was characterized by the same terpenes found in the treatment essential oil used for that animal, regardless of pathway of exposure. The terpenes appear to be transferred unaltered into the milk, regardless of the

Received December 19, 2012.

Accepted March 9, 2013.

${ }^{1}$ Corresponding author: JohanS.Lejonklev@agrsci.dk pathway of exposure. Volatile terpenes in essential oils, which could influence milk flavor, are transferred into milk via both gastrointestinal and respiratory exposure. Key words: caraway, oregano, milk, terpene

\section{INTRODUCTION}

Essential oils are natural plant products obtained through steam distillation of plant material. They contain mainly volatile compounds, including monoterpenes and sesquiterpenes, and have strong flavor and smell (Simon, 1990). Studies done on Origanum vulgare (oregano) plants and Carum carvi (caraway) seeds have shown that they contain large numbers of terpenes in different concentrations, which vary greatly with geographical origin, climate, and harvest time (Grevsen et al., 2009; Laribi et al., 2012). Several studies have shown that a wide variety of terpenes are common in milk and can be related to the botanical composition of the feed (Fernandez et al., 2003; Prache et al., 2005; Tornambé et al., 2006). The composition of mono- and sesquiterpenes in milk can be directly related to the composition of the same compounds in the feed of the animal (Viallon et al., 2000; Bugaud et al., 2001), and their transfer into milk appears to be rapid. Dairy cows that were given forage with high levels of mono- and sesquiterpenes were found to have high levels of these compounds in their milk, with high levels of monoterpenes detected after just $8 \mathrm{~h}$, whereas sesquiterpenes took $32 \mathrm{~h}$ to show up in the milk (Viallon et al., 2000). However, when the high-terpene forage was removed, the terpenes disappeared from the milk after just a few days (Viallon et al., 2000). Similarly, when sheep received terpenes orally, the compounds could not be detected in the milk until $2 \mathrm{~d}$ had passed (Poulopoulou et al., 2012). Tornambé et al. (2006) have shown that the content of terpenes in cow milk increases over a period of 4 wk when grazing diversified pastures. The constituents of essential oils affect the flavor and smell of milk and dairy products only when present at high concentrations (Tornambé et al., 2008), and sesquiterpenes have been found to have a limited effect on milk odor (Moio et al., 1996). But little is known about how 
these volatile compounds make their way from the feed into the milk. Dougherty et al. (1962) used a setup that allowed for either the exposure of the rumen of the animal to a substance or the exposure of its lungs to the volatile components of the substance. The animals were then exposed to off-flavor-producing substances, such as garlic, and the milk was evaluated by a sensory panel. Both pathways resulted in off-flavor in the milk. In a follow-up study, the transfer of several esters and alcohols into milk by exposure to lungs or rumen was studied and evaluated by a sensory panel. Although respiratory exposure resulted in a faster effect $(15 \mathrm{~min}$ as opposed to $30 \mathrm{~min}$ ), no difference could be observed in milk related to the 2 different pathways of exposure (Shipe et al., 1962). Regarding terpenes, Coppa et al. (2011) reported a larger variation for sesquiterpenes than for monoterpenes between milk from different feed treatments, and attributed this to loss of monoterpenes during sample preparation because of their higher volatility. Moio et al. (1996) found a greater increase of sesquiterpenes than monoterpenes in milk from animals on different diets, suggesting that these compounds were mainly absorbed through the gastrointestinal tract rather than the lungs, unlike monoterpenes, which were absorbed through both.

The present study aimed to investigate several volatile terpenes in milk after respiratory or gastrointestinal exposure of dairy cows to essential oils, to elucidate the mode and extent of transfer of terpenes into milk.

\section{MATERIALS AND METHODS}

\section{Animal Treatments and Milk Sampling}

Five Danish Holstein cows with duodenal cannulas and rumen fistula in various stages of lactation, and ranging from 67 to 294 DIM, were studied over $3 \mathrm{wk}$. Animal weight was between 550 and $640 \mathrm{~kg}$, with BCS between 2.9 and 3.2. Feed composition (per $\mathrm{kg}$ of DM), was $320 \mathrm{~g}$ of corn silage, $260 \mathrm{~g}$ of grass silage, $180 \mathrm{~g}$ of barley, $90 \mathrm{~g}$ of soybean meal, $90 \mathrm{~g}$ of rapeseed meal, $40 \mathrm{~g}$ of sugar beet molasses, and $20 \mathrm{~g}$ of minerals. The essential oils used for the study were obtained commercially from New Directions (Hampshire, UK) and were produced by steam distillation of Carum carvi (caraway) seeds and Origanum vulgare (oregano) herbs. Each essential oil was used in 3 different treatments: (1) respiratory exposure, (2) low-level gastrointestinal exposure, and (3) high-level gastrointestinal exposure, for a total of 6 treatments. Respiratory exposure was performed by placing the animal in a chamber as described by Hellwing et al. (2012). Inside the chamber a sponge soaked in $50 \mathrm{~g}$ of essential oil was placed out of reach in front of the animal. For respiratory exposure, the amount was chosen to ensure presence of a clear oregano smell inside the chamber after $9 \mathrm{~h}$. The amounts for gastrointestinal exposure were set to approximately represent a diet of between 1 and $5 \%$ herbs during $1 \mathrm{~d}$, but had to be reduced for oregano because of signs of distress in the animals when the high level was used. The total amounts of essential oils used for the different duodenal levels were 8.28 $\mathrm{g}$ for low-level caraway, $20.7 \mathrm{~g}$ for high-level caraway, $4.14 \mathrm{~g}$ for low-level oregano, and $8.28 \mathrm{~g}$ for high-level oregano. The essential oils used were mixed with 133.2 $\mathrm{g}$ of deodorized sesame oil and divided into 9 plastic bags. One bag was then attached to the duodenum cannula, allowed to fill with intestinal fluid, gently mixed, and then emptied back into the duodenum. This gastrointestinal exposure was spread out over a total of 9 infusions, with approximately $1 \mathrm{~h}$ between each infusion, regardless of level. The control animal received infusions containing deodorized sesame oil only. Animal 1 was assigned as a control for the entire period to determine whether any differences existed between morning and evening milkings and whether airborne transfer of terpenes occurred in the barn. The other animals were subjected to the various treatments in groups of 2, with each treatment lasting 1 wk. During the first week, the treatment used was caraway gastrointestinal exposure. Animals 2 and 3 received low levels, and animals 4 and 5 received high levels. For the second week, the treatment was respiratory exposure. Animals 2 and 3 received caraway, and animals 4 and 5 received oregano. For the final week, oregano gastrointestinal exposure was used. Animals 2 and 3 received low levels, and animals 4 and 5 received high levels. Exposure took place on Mondays immediately after morning milking and lasted for $9 \mathrm{~h}$. Milk samples were collected from each individual animal, morning and evening from Monday to Friday each week, and stored in glass containers at $-20^{\circ} \mathrm{C}$ until analysis. Great care was taken to minimize the risk of contamination of the milk samples by the essential oils used in the treatments. Before all samplings, the udder was washed; for respiratory exposure, the animals were moved from the chambers to a different barn after treatment. Five different sets of milking equipment were used, one assigned to each animal for the duration of each treatment and washed repeatedly between treatments. In addition, all essential oils and the equipment used for handling them were prepared outside the barn and kept in sealed containers when not in use to minimize the risk of air contamination. Milk production was measured for each animal Monday to Friday each of the 3 wk. Feed consumption was measured for each animal starting $2 \mathrm{~d}$ before the start of the experiment and lasting for the duration of the experiment. 


\section{Terpene Analysis}

Terpene analysis was performed using headspace sampling on $50 \mathrm{~g}$ of all milk samples with $1 \mathrm{~mL}$ of 4-methyl-1-pentanol $(5 \mathrm{mg} / \mathrm{L})$ added as internal standard. Essential oils were analyzed in dilution, $1 \mathrm{~mL}$ of oil in $10 \mathrm{~mL}$ of ethanol followed by dilution in Milli-Q water (Millipore, Billerica, MA) to a concentration of $1 \mathrm{mg} / \mathrm{L}$, and undiluted to ensure that compounds present at very low levels would be detected. For diluted essential oils, $1 \mathrm{~mL}$ was used for headspace sampling, and for pure essential oils $<10 \mu \mathrm{g}$ was used. One milliliter of 4-methyl-1-pentanol $(5 \mathrm{mg} / \mathrm{L})$ was also added to diluted essential oils as internal standard. Volatile compounds were collected on Tenax-TA traps. The traps contained $250 \mathrm{mg}$ of Tenax-TA with mesh size 60/80 and a density of $0.37 \mathrm{~g} / \mathrm{mL}$ (Buchem bv, Apeldoorn, the Netherlands). Samples were equilibrated to $50 \pm 1^{\circ} \mathrm{C}$ in a circulating water bath and then purged with nitrogen flow $(200 \mathrm{~mL} / \mathrm{min})$ for $60 \mathrm{~min}$. The same nitrogen flow was then used to dry the traps for 20 min to remove excess water. The trapped volatiles were desorbed using an automatic thermal desorption unit (ATD 400, Perkin Elmer, Norwalk, CT). Primary desorption was carried out by heating the trap to $250^{\circ} \mathrm{C}$ with a flow $(60$ $\mathrm{mL} / \mathrm{min}$ ) of carrier gas $\left(\mathrm{H}_{2}\right)$ for $15.0 \mathrm{~min}$. The stripped volatiles were trapped in a Tenax TA cold trap (30 $\mathrm{mg}$, held at $5^{\circ} \mathrm{C}$ ), which was subsequently heated at $300^{\circ} \mathrm{C}$ for $4 \mathrm{~min}$ (secondary desorption, outlet split 1:10). This allowed for rapid transfer of volatiles to a GC-MS gas chromatograph-mass spectrometer (7890A GC-system interfaced with a 5975C VL MSD with triple-axis detector, Agilent Technologies, Palo Alto, $\mathrm{CA})$ through a transfer line heated to $225^{\circ} \mathrm{C}$. Separation of volatiles was carried out on a DB-Wax capillary column $(30 \mathrm{~m}$ long $\times 0.25 \mathrm{~mm}$ internal diameter, 0.50 $\mu \mathrm{m}$ film thickness, Agilent Technologies). The column pressure was held constant at $16,550 \mathrm{~Pa}$, resulting in an initial flow rate of approximately $1.2 \mathrm{~mL} / \mathrm{min}$ using hydrogen as the carrier gas. The column temperature program was as follows: $10 \mathrm{~min}$ at $40^{\circ} \mathrm{C}$, from $40^{\circ} \mathrm{C}$ to $240^{\circ} \mathrm{C}$ at $8^{\circ} \mathrm{C} / \mathrm{min}$, and finally $5 \mathrm{~min}$ at $240^{\circ} \mathrm{C}$. The mass spectrometer was operating in electron ionization mode at $70 \mathrm{eV}$ and with a gain factor of 8. Mass-tocharge ratios between 15 and 300 were scanned. The 14 terpenes were identified using external standards. Low boiling point calibration sample no. 2 (Agilent Technologies) was used to calculate the Kovats (retention) index for the standards. The terpene compound standards used were $\alpha$-pinene $(\geq 99 \%$, Sigma-Aldrich, St. Louis, MO), $\beta$-pinene ( $\geq 99 \%$, Fluka, Buchs, Switzerland), 3-carene $(\geq 98.5 \%$, Fluka), myrcene $(\geq 90 \%$, Aldrich), $\alpha$-terpinene (97\%, Fluka), limonene $(\geq 99 \%$, Fluka), $\gamma$-terpinene $(\geq 97 \%$, Fluka), $\rho$-cymene (99\%,
Aldrich), terpinolene ( $\geq 98 \%$, Aldrich), $\beta$-caryophyllene ( $\geq 80 \%$, Aldrich), $\alpha$-humulene (98\%, Fluka), $\alpha$-terpineol ( $\geq 96 \%$, Aldrich), carvone ( $\geq 97 \%$, Aldrich), and carvacrol ( $\geq 98 \%$, Aldrich). The software program, MSD Chemstation (version E.02.00, Agilent Technologies), was used for analysis of chromatographic data.

\section{Data Analysis}

Results for diluted essential oils are presented as mean peak areas of 2 measurements. For milk samples, all individual peak areas were $\log _{10}$-transformed before analysis to ensure homogeneity of variance. One sample of high-level caraway via duodenum treatment (evening milk after treatment) was removed before analysis because of abnormally low levels of terpenes. The sum of log peak areas for the 14 terpenes in milk samples from each animal and milking time were analyzed for variance using Proc Mixed (SAS Institute Inc., Cary, NC) within each treatment, where milk sampling times were compared using a model with time as class variable and with cow as random to account for repeated measurements. For the control, effect of milk sampling time was analyzed using a model with time and week as class variables. In both models, sampling time 2 (immediately after treatment) was contrasted to time 1 and 3 (before treatment and the next morning after treatment), and time 1 (before treatment) was contrasted against time 3 (next morning after treatment). In addition data for the 14 individual terpenes were explored by principal components analysis (PCA). The PCA was performed on UV scaled data in Simca P+ ver. 12 (Umetrics, Umeå, Sweden).

\section{RESULTS AND DISCUSSION}

\section{Animals and Essential Oils}

Dry matter intake for the duration of the experiment, based on 105 measurements, was $24.3 \pm 2.2$ $\mathrm{kg} / \mathrm{d}$. Milk production, based on 70 measurements, was $28.3 \pm 6.6 \mathrm{~kg} / \mathrm{d}$. No effects on DMI or milk production were observed for any of the treatments. The results of analysis of the essential oils are presented in Table 1 . The results were consistent with published data, with the monoterpenes carvacrol and $\rho$-cymene being most abundant in oregano (Grevsen et al., 2009) and carvone and limonene being most abundant in caraway (Laribi et al., 2012). But high levels of carvacrol were also found in caraway, which may be due to differences in geographical origin, climate, or harvest time compared with the referenced studies. All of the monoterpenes analyzed were found in both essential oils, if not in diluted oils, then in the pure oil. The sesquiterpene 
Table 1. Gas chromatography-mass spectrometry peak area (mean \pm SD) of 12 monoterpenes, and 2 sesquiterpenes in caraway and oregano essential oils

\begin{tabular}{lccc}
\hline Compound & $\begin{array}{c}\text { Kovats } \\
\text { index }\end{array}$ & Caraway & Oregano \\
\hline Monoterpene & & & \\
$\alpha$-Pinene & 1,020 & $41,000 \pm 2,000$ & $40,000 \pm 4,000$ \\
$\beta$-Pinene & 1,109 & $\mathrm{ND}^{1,2}$ & $10,000 \pm 3,000$ \\
3-Carene & 1,158 & $19,000 \pm 600$ & $15,000 \pm 2,000$ \\
Myrcene & 1,181 & $5,000 \pm 1,000$ & $7,000 \pm 900$ \\
$\alpha$-Terpinene & 1,187 & $4,000 \pm 500$ & $3,000 \pm 600$ \\
Limonene & 1,203 & $350,000 \pm 170,000$ & $32,000 \pm 6,000$ \\
$\gamma$-Terpinene & 1,266 & $\mathrm{ND}^{1,2}$ & $28,000 \pm 100$ \\
$\rho$-Cymene & 1,295 & $\mathrm{ND}^{1,2}$ & $5,000 \pm 27,000$ \\
Terpinolene & 1,306 & $4,000 \pm 1,000$ & $5,000 \pm \pm 00$ \\
$\alpha$-Terpineol & 1,723 & $960,000 \pm 110,000$ & $5,000 \pm 700$ \\
Carvone & 1,767 & $210,000 \pm 76,000$ & $1,400,000 \pm 89,000$ \\
Carvacrol & - & $8,000 \pm 600$ & $15,000 \pm 200$ \\
Sesquiterpene & 1,618 & $\mathrm{ND}^{1}$ & $5,000 \pm 300$ \\
$\beta$-Caryophyllene & 1,694 & & \\
$\alpha$-Humulene & & &
\end{tabular}

$\beta$-caryophyllene was only detected in oregano, whereas the other sesquiterpene, $\alpha$-humulene, was detected in both essential oils, albeit at relatively low levels.

\section{Terpenes in Milk}

The total terpene level did not differ in control milk for any of the analyzed sampling times. Results from analysis of terpene compounds in treatment milk are presented in Figure 1. The values presented are the sum of $\log _{10}$-transformed total peak areas for the 12 monoterpenes and 2 sesquiterpenes analyzed. Only results for the first 3 milkings, 1 before treatment and 2 after, are included. As expected, all milk samples contained terpenes in various concentrations, likely acquired from the feed of the animals (Fernandez et al., 2003; Prache et al., 2005; Tornambé et al., 2006). The total terpene levels in milk obtained immediately after treatment showed an increase for all treatments compared with milk obtained from before treatment and from the next morning's milking $(P<0.05)$, except for the treatment with caraway via respiratory exposure, in which the terpene levels did not appear to increase $(P>0.10)$. However, when milk obtained from before treatment was compared with milk from the next morning, we found no differences except for the treatment with oregano via respiratory exposure $(P$ $=0.06)$. These results indicate that the transfer of the terpene components into the milk was fast but shortlived. Shipe et al. (1962) found respiratory exposure to result in a faster effect in milk than rumen exposure. This was not tested in our study, but both respiratory and gastrointestinal pathways of exposure were found to occur within 9 h. However, in all the studies referenced, terpenes were included in feed, thus the gastrointestinal part of the exposure to essential oils begins in the rumen of the animals. In our study, essential oils were infused into the duodenum of the animal, bypassing the rumen altogether. This approach was chosen as it has been found that eructated gases from the rumen end up in the lungs of the animal by means of rumination (Dougherty et al., 1962), which would have made pure gastrointestinal exposure impossible if the essential oils had been added to the rumen. Caution must therefore be exercised when comparing the earlier studies to the current study, as a rumen effect might need to be considered. It is possible that the transfer of terpenes is faster when they are directly introduced into the duodenum rather than the rumen. Other studies have exposed cows to terpenes in feed for longer periods, and Viallon et al. (2000) found increased levels of monoterpenes in milk after $8 \mathrm{~h}$ from the start of exposure, similar to the present study, although maximal effect was obtained after 4 d. Poulopoulou et al. (2012) noted that even longer exposure times were required before the maximal effect of addition of terpenes to feed on milk terpene content was obtained. Tornambé et al. (2006) reported an increase in certain terpenes during a 4 -wk period of grazing diversified pastures, and this increase is, to some extent, ascribed to increases in the terpene content of plant material. In the present study, the time of exposure was limited to $9 \mathrm{~h}$, and exposure for several days might have resulted in higher terpene concentrations in milk. The disappearance of terpenes in milk after treatment was more rapid in the present study compared with those of Poulopoulou et al. (2012) 


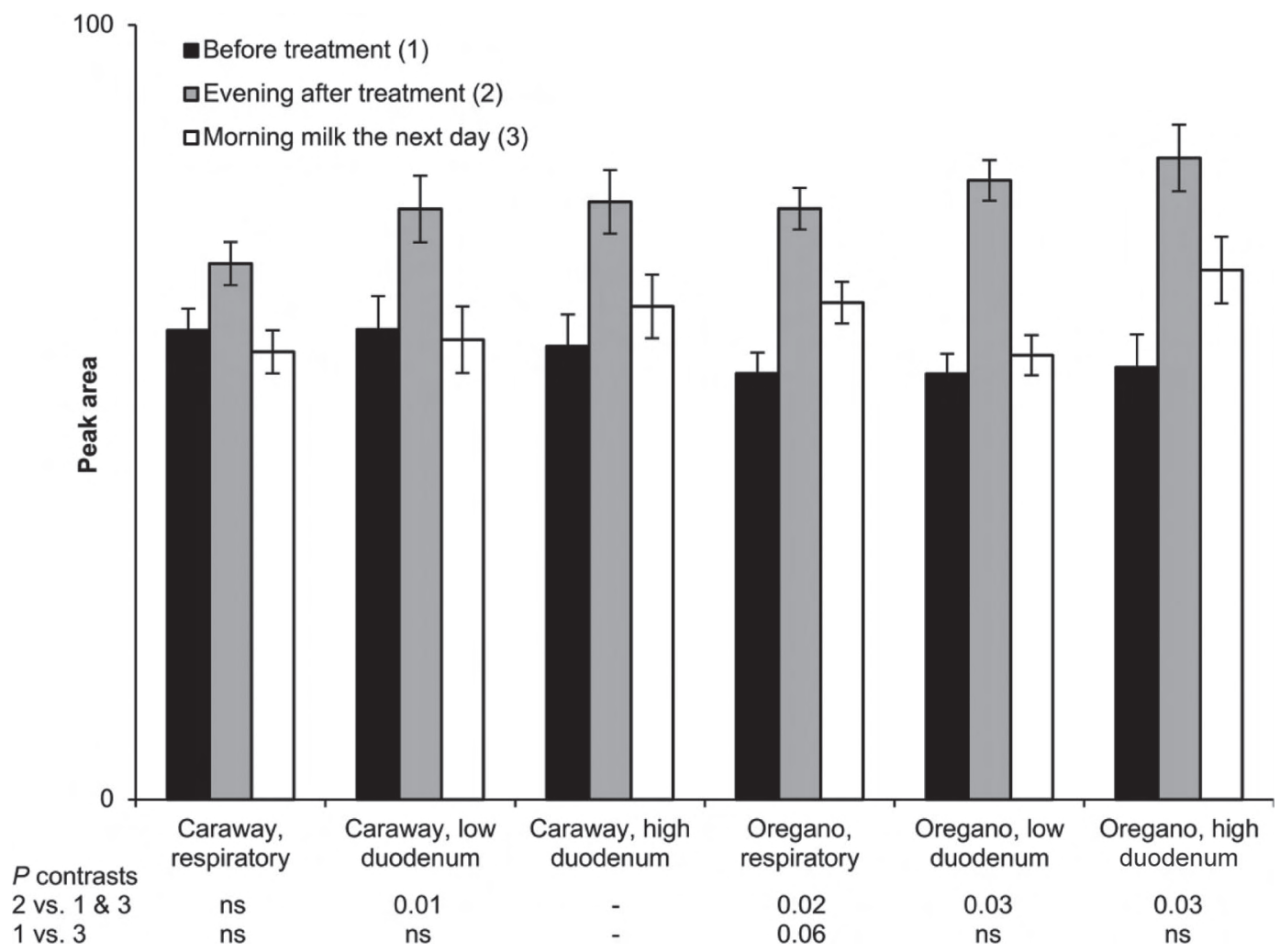

Figure 1. $\log _{10}$-transformed sum of peak areas (least square means $\pm \mathrm{SE}$ ) for all 14 terpenes analyzed in milk samples. $P$-values below bars indicate level of significance for contrasts.

as well as Viallon et al. (2000), which could be related to the longer exposure. In addition to being transferred and excreted into milk, terpene compounds are expected to be metabolized into more polar compounds, followed by excretion in urine (Sapra et al., 2008).

\section{Principal Component Analysis}

The PCA was used to further elucidate the differences between the milk samples from the various treatments, as well as the specific terpenes involved. Figures 2 and 3 display the scores plot and the loadings plot, respectively, for the PCA of the terpenes found in the milk samples. The first principal component (PC1) described $49.7 \%$ of the variation of the 14 analyzed compounds in the milk samples and the second principal component (PC2) described 25.9\%. The scores plot (Figure 2) shows the control samples in the lower left of the plot. Oregano-treated samples were separated from caraway and control samples by PC1, whereas carawaytreated samples were separated from the control by PC2. For both essential oils, gastrointestinal treatment resulted in a greater effect than respiratory treatment and, for the oregano treatments, the higher level of duodenal infusion resulted in a higher effect than the low dose. Terpenes are transferred both by respiratory and gastrointestinal exposure, and although previous studies could not distinguish between the 2 pathways using sensory panels (Shipe et al., 1962), use of GC-MS analysis revealed a difference. This difference was due to the lower total levels of the 14 terpenes in the respiratory treatment milk samples (Figure 1). The transfer of terpenes into milk via the lung pathway is dependent on their presence in the air and thus their volatility, whereas in the gastrointestinal pathway, essential oil is infused directly into the duodenum, which could explain the reduced treatment effect on respiratory samples compared with gastrointestinal samples. The total amounts of essential oils absorbed by the respiratory pathway were indeed most likely less that the amounts introduced in the duodenum. The loadings plot (Figure 3 ) reveals that the compounds analyzed in milk samples had positive loadings on PC1 for most of the terpenes, except carvone and limonene, which had small negative loadings on PC1 and high positive loadings on PC2. Therefore, caraway milk samples could be characterized by a higher content of carvone and limonene compared with the control and oregano milk samples. This is consistent with the much higher content of these 2 terpenes in caraway essential oil compared with oregano 


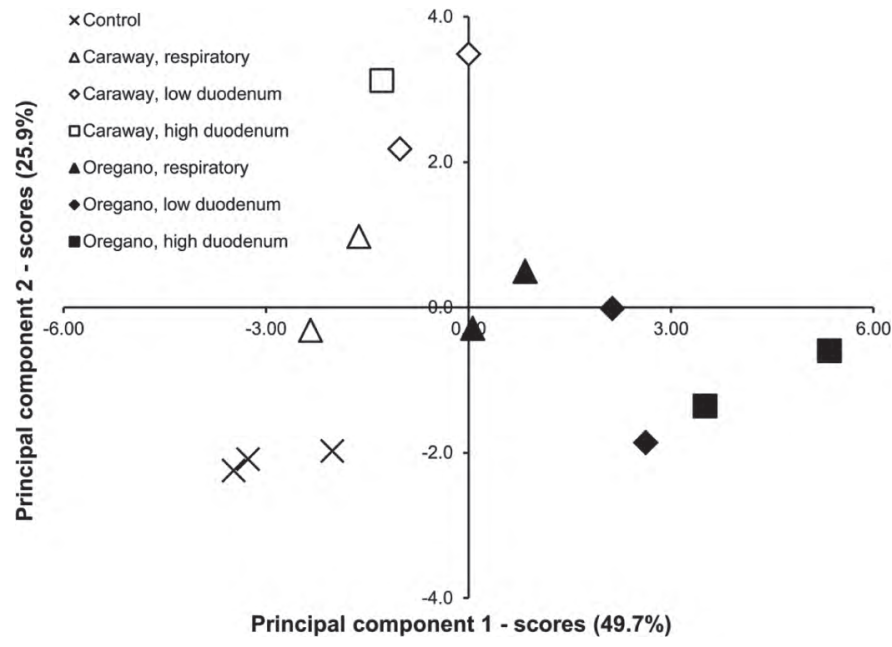

Figure 2. Scores plot describing the relationships among milk samples from dairy cows subjected to different essential oil treatments using principal component analysis, based on logarithmic peak area signal response values from GC-MS analysis of 14 terpenes.

essential oil (Table 1). The high loadings on both PC1 and $\mathrm{PC} 2$ for 3-carene, terpinolene, and myrcene show that both essential oil treatments result in an increase of these compounds in milk, although only 3 -carene was present in similar amounts in the 2 oils. The loadings of $\alpha$-terpineol and carvacrol were much lower than those of the other terpenes. The variation in content of these 2 compounds between samples should be regarded as mainly random, although carvacrol was abundant in both essential oils. The high PC1 loadings of all other terpenes could be related to oregano essential oil treatments. These terpenes were present in higher amounts in oregano essential oil than in caraway essential oil, except $\alpha$-pinene, which was present in similar concentrations in both oils. The fact that several of the terpenes detected in the essential oils were found in the milk suggests that these compounds are transferred unaltered into the milk. These findings are in line with existing literature reporting that the most abundant terpenes in feed are also the most abundant in milk, although proportions are nonidentical (Viallon et al., 2000; Bugaud et al., 2001; Fernandez et al., 2003; Tornambé et al., 2008). Although the oil-air partition coefficient varies greatly between individual monoterpenes (Falk et al., 1990), it is difficult to relate the partition coefficients to the results obtained in the present study. The results appear to be more dependent on the amounts in the essential oils than on the chemical properties of the monoterpenes. Other studies found differences between monoterpenes and sesquiterpenes when ruminants received them orally or in feed, with monoterpenes being transferred faster into milk (Viallon et al., 2000) and to a higher degree (Poulopoulou et al., 2012). Such an effect could not be observed in this study. Oregano gastrointestinal exposure could be characterized by a higher content of the 2 sesquiterpenes, $\beta$-caryophyllene and $\alpha$-humulene, because of their high positive loadings for PC1 and negative loadings for PC2. Sesquiterpenes appear to be transferred just as fast and as readily as monoterpenes, but only for gastrointestinal exposure. This is likely due to the lower volatility (Coppa et al., 2011) and higher lipophilicity (Tschiggerl and Bucar, 2010) of sesquiterpenes, compared with monoterpenes, which would reduce these compounds in respiratory exposure compared with gastrointestinal exposure.

\section{CONCLUSIONS}

This study has shown that terpenes present in essential oils can be transferred unaltered into cow's milk when the animals receive them by gastrointestinal or respiratory exposure. The resulting effect on the terpene profile of the milk was dependent on which essential oils were used for the treatment, as well as the pathway of exposure. The effect of the treatment was immediately observed in milk samples after exposure. However, by the next day, terpene components in the milk had reverted back to levels closer to those found before treatment. This indicates that the time required for transfer of these volatile compounds into milk is measured in hours. Additional research is required to determine the potential positive effects of these essential oils as well as the long-term effect of the treatments.

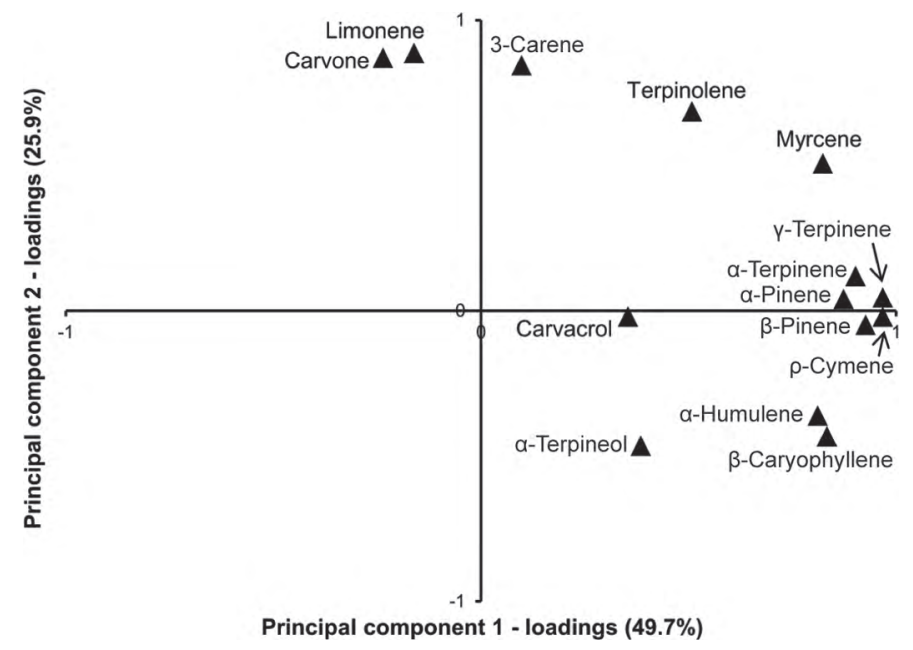

Figure 3. Loadings plot describing the relationships among terpenes analyzed in milk from dairy cows subjected to different essential oil treatments using principal component analysis, based on logarithmic peak area signal response values from GC-MS analysis. 


\section{ACKNOWLEDGMENTS}

The authors acknowledge financial support from The Danish Ministry of Food, Agriculture and Fisheries (Copenhagen, Denmark), Arla Foods (Viby, Denmark), and DLF Trifolium (Store Heddinge, Denmark).

\section{REFERENCES}

Bugaud, C., S. Buchin, J.-B. Coulon, A. Hauwuy, and D. Dupont. 2001. Influence of the nature of alpine pasture on plasmin activity, fatty acid and volatile compound composition of milk. Lait 81:401-414.

Coppa, M., B. Martin, P. Pradel, B. Leotta, A. Priolo, and V. Vasta. 2011. Effect of a hay-based diet or different upland grazing systems on milk volatile compounds. J. Agric. Food Chem. 59:4947-4954.

Dougherty, R. W., W. F. Shipe, G. V. Gudnason, R. A. Ledford, R. D. Petersen, and R. Scarpellino. 1962. Physiological mechanisms involved in transmitting flavors and odors to milk. I. Contribution of eructated gases to milk flavour. J. Dairy Sci. 45:472-476.

Falk, A., E. Gullstrand, A. Löf, and E. Wigaeus-Hjelm. 1990. Liquid/air partition coefficients of four terpenes. Br. J. Ind. Med. 47:62-64.

Fernandez, C., C. Astier, E. Rock, J.-B. Coulon, and J.-L. Berdague. 2003. Characterization of milk by analysis of its terpene fractions. Int. J. Food Sci. Technol. 38:445-451.

Grevsen, K., X. C. Frette, and L. P. Christensen. 2009. Content and composition of volatile terpenes, flavonoids and phenolic acids in Greek oregano (Origanum vulgare L. ssp. hirtum) at different development stages during cultivation in cool temperate climate. Eur. J. Horticult. Sci. 74:193-203.

Hellwing, A. L., P. Lund, M. R. Weisbjerg, M. Brask, and T. Hvelplund. 2012. Technical note: Test of a low-cost and animal-friendly system for measuring methane emissions from dairy cows. J. Dairy Sci. 95:6077-6085.
Laribi, B., K. Kouki, T. Bettaieb, A. Mougou, and B. Marzouk. 2012. Essential oils and fatty acids composition of Tunisian, German and Egyptian caraway (Carum carvi L.) seed ecotypes: A comparative study. Ind. Crops Prod. 41:312-318.

Moio, L., L. Rillo, A. Ledda, and F. Addeo. 1996. Odorous constituents of ovine milk in relationship to diet. J. Dairy Sci. 79:1322-1331.

Poulopoulou, I., E. Zoidis, T. Massouras, and I. Hadjigeorgiou. 2012. Terpenes transfer to milk and cheese after oral administration to sheep fed indoors. J. Anim. Physiol. Anim. Nutr. (Berl.) 96:172181.

Prache, S., A. Cornu, J. L. Berdague, and A. Priolo. 2005. Traceability of animal feeding diet in the meat and milk of small ruminants. Small Rumin. Res. 59:157-168.

Sapra, B., S. Jain, and A. K. Tiwary. 2008. Percutaneous permeation enhancement by terpenes: Mechanistic view. AAPS J. 10:120-132.

Shipe, W. F., R. A. Ledford, R. D. Petersen, R. A. Scanlan, H. F. Geerken, R. W. Dougherty, and M. E. Morgan. 1962. Physiological mechanisms involved in transmitting flavors and odors to milk. II. Transmission of some flavor components of silage. J. Dairy Sci. 45:477-480.

Simon, J. E. 1990. Essential oils and culinary herbs. Pages 472-483 in Advances in New Crops. J. Janick and J. E. Simon, ed. Timber Press, Portland, OR.

Tornambé, G., A. Cornu, P. Pradel, N. Kondjoyan, A. P. Carnat, M. Petit, and B. Martin. 2006. Changes in terpene content in milk from pasture-fed cows. J. Dairy Sci. 89:2309-2319.

Tornambé, G., A. Cornu, I. Verdier-Metz, P. Pradel, N. Kondjoyan, G. Figueredo, S. Hulin, and B. Martin. 2008. Addition of pasture plant essential oil in milk: Influence on chemical and sensory properties of milk and cheese. J. Dairy Sci. 91:58-69.

Tschiggerl, C., and F. Bucar. 2010. Investigation of the volatile fraction of rosemary infusion extracts. Sci. Pharm. 78:483-492.

Viallon, C., B. Martin, I. Verdier-Metz, P. Pradel, J. P. Garel, J. B. Coulon, and J. L. Berdague. 2000. Transfer of monoterpenes and sesquiterpenes from forages into milk fat. Lait $80: 635-641$. 